\title{
Posterior Fossa Intra-Axial Tumors: Surgical Outcomes
}

\author{
ALI R. HAMDAN, M.D.* and ABD EL-HAKEEM A. ESSA, M.D.** \\ The Department of Neurosurgery, Faculty of Medicine, South Valley University, Qena* and Assiut** Universities, Assiut, Egypt
}

\begin{abstract}
Background: Central nervous system tumors are the most common solid tumors in children; posterior fossa tumors in children account for about $54 \%-70 \%$ of all brain tumors, while $15 \%$ to $20 \%$ of adult brain tumors occur in the posterior fossa.
\end{abstract}

Aim of Study: To document the short-term surgical outcomes of posterior fossa intra-axial tumors in patients presented with manifestations of raised intracranial pressure, brain stem and or cerebellar compression.

Patients and Methods: Thirty patients diagnosed with posterior fossa intra-axial tumors, presented to Neurosurgery departments, Qena University Hospital, South Valley University and Assiut university hospital, from January 2014 to January 2016 were enrolled in this study. Complete clinical and neuroimaging evaluation of the patients was done. All patients underwent microscopic surgical excision. Patients were followed-up clinically and radiologically immediately and within one month postoperatively. The complications noted were documented. The statistical analysis was done using SPSS software (version 16.0).

Results: This study included 22 children and eight adults with a mean age $19.367 \pm 18.213$ (SD). Increased intracranial pressure and/or ataxia were the main manifestations. Twentyone patients showed significant post-operative symptomatic improvement when compared with pre-operative conditions, while the remaining nine patients showed either no improvement or more severely affected afterward two of them have died. Hydrocephalus was the most common post-operative complications and managed by insertion of a ventriculoperitoneal shunt.

Conclusion: The surgical outcome of patients with intraaxial posterior cranial fossa tumors is good due to early correct diagnosis, the advent of microsurgical techniques, proper selection of the appropriate surgical approach and the proper treatment of post-operative complications.

Key Words: Brain tumors - Posterior cranial fossa - Intraaxial-Surgical treatment.

Correspondence to: Dr. Ali R. Hamdan,

The Department of Neurosurgery, Faculty of Medicine, South Valley University, Qena, Egypt

\section{Introduction}

CENTRAL nervous system tumors are the most common solid tumors in children; posterior fossa tumors in children account for about $54 \%-70 \%$ of all brain tumors, while $15 \%$ to $20 \%$ of adult brain tumors occur in the posterior fossa [1].

Certain types of posterior fossa tumors (PFT), such as medulloblastoma, pilocytic astrocytomas and ependymomas occur more frequently in children, while tumors including metastatic lesions, lymphomas, and hemangioblastoma more commonly affect adults than children [2] .

Manifestations of posterior fossa tumors such as ataxia, vomiting, vertigo and chocking commonly caused by focal compression of the cerebellum or brain stem centers and increased intracranial pressure including; drowsiness, headache, imbalance, nausea, vomiting, and symptoms may also occur when the tumor damages local structures, such as cranial nerves may include; dilated pupils, eye problems, face muscle weakness, loss of feeling in part of the face, hearing loss, unsteadiness when walking, taste problems, and vision problems [3].

Excision of posterior fossa tumors is indicated for the following goals: To decompress the posterior fossa for the purpose of relieving pressure on the brain stem and/or to release intracranial pressure and avoid the risk of herniation, for histopathological diagnosis of the tumor, to determine further plan of management depending on the nature of the tumor and when indicated, to treat hydrocephalus by shunting cerebrospinal fluid (External CSF drainage, endoscopic third venriculostomy (E.T.V) or even no drainage is considered in some cases. Still, many disagree regarding the ideal shunting procedure $[4,5]$. 
Hydrocephalus occurs in approximately $71 \%$ $90 \%$ of pediatric patients with posterior fossa tumors; after tumor resection, about 10\%-40\% demonstrate persistent hydrocephalus [6].

\section{Patients and Methods}

This retrospective study has been conducted on thirty patients at the Neurosurgery departments. Qena University Hospital, South Valley University and Assiut University Hospital from January 2014 to January 2016. An informed signed consent was taken from all the patients(and from the children's parents for the children's images to appear in the article) before enrolling them into the study after approval of the Ethical Committee of Faculty of Medicine, South Valley University. The data regarding age, sex, clinical manifestations, radiological findings surgical techniques and histopathological results were collected during the study period.

Surgical technique involved positioning of the patient prone, on the table with support to thorax, pelvis, and legs. This support should leave the belly free. The head was fixed in a Mayfield clamp as shown in Fig. (1A). More flexion of the head was done to give better exposure to the lower occiput and neck. Midline skin incision was done, from $2 \mathrm{~cm}$ above the external occipital protuberance, down to the posterior arch of $\mathrm{C} 1$ as shown in Fig. (1B). The spinous process of $\mathrm{C} 2$ was not exposed to maintain its ligamentous and muscular attachment, as subsequent surgery and radiotherapy may result in progressive cervical instability.

Sub-occipital craniectomy was done for five cases only and a craniotomy flap was done for the remaining cases. A craniotomy flap was done by using a high-speed drill as follow, we made a burr hole beside the midline just under the presumed position of the underlying transverse sinus then, using the high-speed craniotome, to make a bone flap which was extended through the foramen magnum. A " $Y$ " shape dural opening over both hemispheres was done, with the "long leg" of the $\mathrm{Y}$ in the midline with ligation of the occipital sinus in the midline. The microscope then brought into the field after reflection of the dura with the opening of the cisterna magna to drain CSF.

Fourth ventricular tumors were approached through the telovaler approach only one case at the beginning of our work was approached through the vermis. Through the telovaler approach, dissection started on one side, medial to the tonsil, between the tonsil and the uvula. Gradual resection of the tumor bulk was done, and any tumor in the floor of the fourth ventricles was reduced as much as possible without disruption of the floor to avoid any neurological deficit.

The trans-cortical approach was done for tumors in the cerebellar hemispheres with gross total resection of the tumor, the capsule also in case of the cystic tumor was resected.

Hemostasis was obtained with the use of oxidized methylcellulose and coagulation by diathermy was reduced as possible.

The dura was closed as watertight as possible, primarily without causing compression or duroplasty was made if there was tightness or compression on the cerebellar hemispheres.

Ventriculoperitoneal shunt insertion was done urgently in some patients before tumor excision if the patient developed acute disturbance of conscious level as shown in Fig. (e2).

Following surgery, specimens were sent for histopathological evaluation. All patients were admitted to intensive care unit immediately postoperative with meticulous follow-up for the conscious level. Clinical and radiological follow-up was done immediately and one month postoperatively .

\section{Statistical analysis:}

Statistical analyses were performed using SPSS version 16 . The data were presented as the average and mean \pm standard deviation.

\section{Results}

Regarding gender 17 (56.5\%) patients were males and $13(43.5 \%)$ patients were females, with their ages ranged from 11 months to 59 years with an average 17.17 years, and mean of $19.367 \pm 18.213$ (SD). Children are more commonly affected 22 $(73.3 \%)$ than adults $8(26.66 \%)$ patients.

Clinically, 27 (90\%) patients out of 30 were presented with symptoms of increased intracranial tension (headache, vomiting, and blurring of vision), while $22(75 \%)$ patients complained of equilibrium disturbances and $12(40 \%)$ patients complained of vertigo. By examinations, 28 (93.3\%) patients had cerebellar syndrome, hydrocephalic changes were found in 12 (40\%) Patients, 6 (20\%) patients had cranial nerve dysfunction and only one $(3.33 \%)$ patient was presented with disturbed conscious level as shown in Table (1). 
For the hydrocephalic changes which were documented in 12 patients, an urgent ventriculoperitoneal shunt was inserted for three patients, an external drain was used for four patients, while for the other five cases the tumors were attacked directly with no need for any shunting procedures.

Many surgical approaches were done for excision, telovelar approach was the commonest one which was done for $24(80 \%)$ patients, followed by trans-cerebellar approach which was done for three cases $(10 \%)$, retrosigmoid was done for one $(3.33 \%)$ patient, Trans-vermian was done for one $(3.33 \%)$ patient and partial aspiration of the cyst and removal of the cyst wall was done for one $(3.33 \%)$ patient as shown in Table (2).

Regarding the post-operative complications, six $(20 \%)$ patients were complicated with postoperative hydrocephalus, secondary to cerebellar oedema and/or fourth ventricular haematoma and treated surgically by ventriculoperitoneal shunt, four $(13.33 \%)$ patients were presented with postoperative CSF leak, three (10\%) patients had bulbar palsy, death was recorded in two $(6.66 \%)$ patients, one $(3.33 \%)$ patient was presented with wound infection, and one $(3.33 \%)$ patient was presented with cerebellar mutism as shown in Table (1).

The Post-operative histopathological results were as follow; the most common type was medulloblastoma $(\mathrm{n}=12,40 \%)$, followed by Pilocytic astrocytoma $(\mathrm{n}=10,33.3 \%)$, anaplastic astrocytoma $(\mathrm{n}=4,13.3 \%)$, metastatic adenocarcinoma $(\mathrm{n}=2$, $6.66 \%)$, anaplastic ependymoma $(\mathrm{n}=1,3.33 \%)$ and haemangioplastoma $(\mathrm{n}=1,3.33 \%)$ as shown in Table (3).

Through post-operative follow-up; immediately and within one month later, 24 patients showed significant symptomatic improvement when com-

Table (2): Surgical approaches.

\begin{tabular}{lcc}
\hline Approach & Number of patients & Percentage \\
\hline Telovelar & 24 & 80 \\
Transcerebellar & 3 & 10 \\
Retrosigmoid & 1 & 3.33 \\
Transvermian & 1 & 3.33 \\
Partial cystic aspiration & 1 & 3.33 \\
\hline
\end{tabular}

pared with pre-operative conditions, while the remaining 6 patients showed either no improvement or more severely affected. Two patients have died, one of them was male patient 10 years old with posterior fossa medulloblastoma died 20 days postoperative, secondary to chest infection and aspiration and the other was 55 years old with posterior fossa metastatic adenocarcinoma died one month post-operative due to multiple organ metastasis.

Table (1): Demographic and clinical data.

\begin{tabular}{|c|c|c|c|}
\hline Information & Number & ercentage & Mean $\pm \mathrm{SD}$ \\
\hline \multicolumn{4}{|l|}{ Sex: } \\
\hline Male & 17 & 56.5 & \\
\hline Female & 13 & 43.5 & \\
\hline Child & 22 & 73.33 & \\
\hline Adult & 8 & 26.66 & \\
\hline Age & $\begin{array}{l}11 \mathrm{~m}-59 \\
\text { year }\end{array}$ & & $\begin{array}{l}19.367 \pm \\
18.213\end{array}$ \\
\hline $\begin{array}{l}\text { Symptoms: } \\
\text { • Symptoms of ICH }\end{array}$ & & & \\
\hline $\begin{array}{l}\text { - (Vomiting, headache, } \\
\text { and blurring of vision) } \\
\text { - Equilibrium disturbances }\end{array}$ & $\begin{array}{l}27 \\
22\end{array}$ & $\begin{array}{l}90 \\
75\end{array}$ & \\
\hline - Vertigo & 12 & 40 & \\
\hline \multicolumn{4}{|l|}{ Signs: } \\
\hline - Cerebellar syndrome & 28 & 93.3 & \\
\hline - Hydrocephalic changes & 12 & 40 & \\
\hline - Cranial nerve dysfunction & 6 & 20 & \\
\hline - Disturbed conscious level & 1 & 3.33 & \\
\hline \multicolumn{4}{|l|}{ Complications: } \\
\hline $\begin{array}{l}\text { Post-operative } \\
\text { hydrocephalus }\end{array}$ & 6 & 20 & \\
\hline - CSF Leak & 4 & 13.33 & \\
\hline - Bulbar palsy & 3 & 10 & \\
\hline - Death & 2 & 6.66 & \\
\hline - Wound infection & 1 & 3.33 & \\
\hline - Mutism & 1 & 3.33 & \\
\hline
\end{tabular}

Table (3): Post-operative histopathology.

\begin{tabular}{lcc}
\hline Pathology & Number of patients & Percentage \\
\hline Medulloblastoma & 12 & 40 \\
Pilocytic astrocytoma & 10 & 33.3 \\
Anaplastic astrocytoma & 4 & 13.33 \\
Metastatic adenocarcinoma & 2 & 6.66 \\
Anaplastic ependymoma & 1 & 3.33 \\
Hemangioblastoma & 1 & 3.33 \\
\hline
\end{tabular}



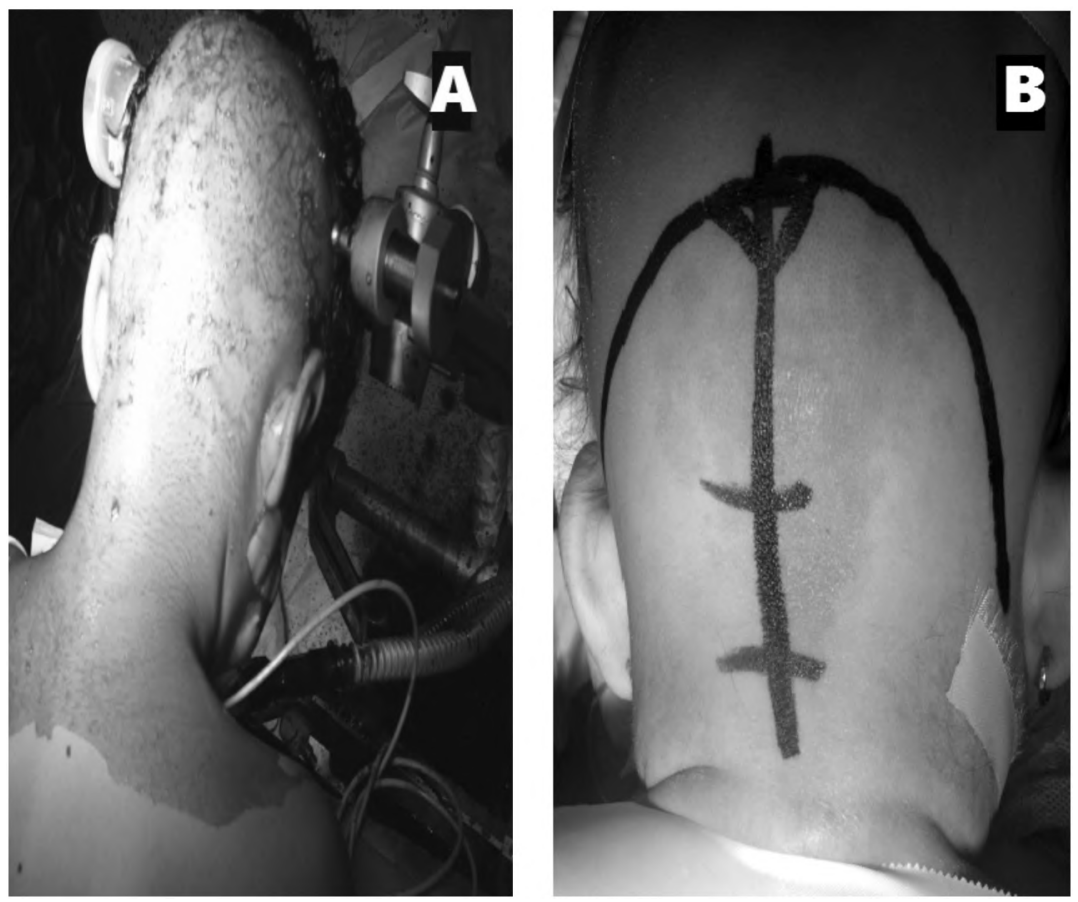

Fig. (1): (A) A photograph for 10 years old boy in prone position with head of the patient fixed tightly in a Mayfield clamps. (B) A photograph for 11 months old girl in prone position with surface marking of the midline skin incision $2 \mathrm{~cm}$ above the external protuberance, down to the spinous process of C2 Fig. (1).
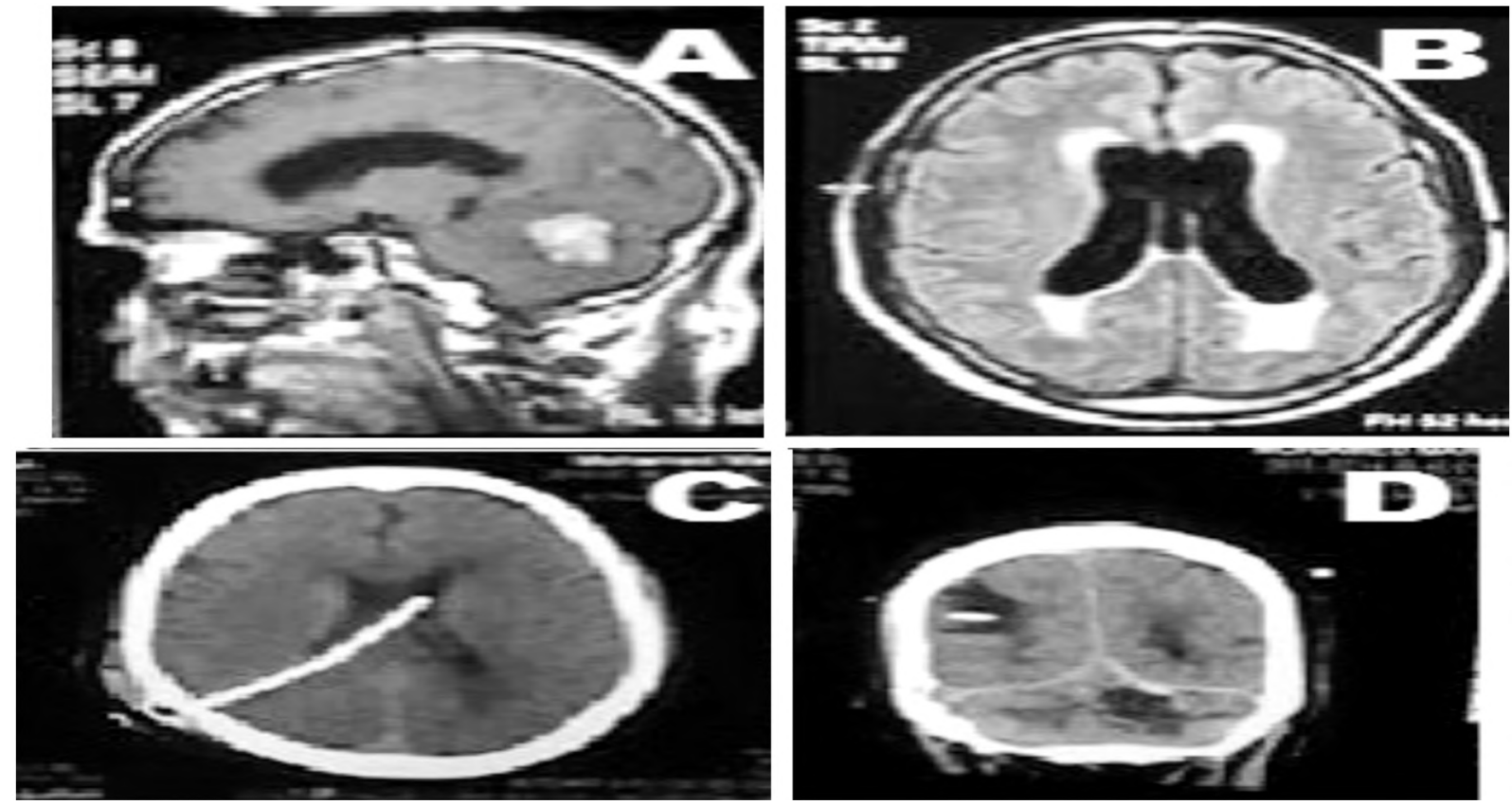

Fig. (2): Male patient 55 years old presented with ataxia and severe intolerable headache. (A) Preoperative MRI brain T1 sagittal view with contrast showing cerebellar hyperintense S.O.L. (B) Pre-operative MRI Flair Axial view showing hydrocephalus. (C) Post-operative Plain CT brain axial view showing RT. Ventriculoperitoneal shunt was done before tumor excision. (D) Post-operative plain brain Coronal view showing excised the preexisting mass. with Rt. Proximal catheter of VP shunt.

\section{Discussion}

A posterior fossa tumor is one of the most devastating forms of brain tumors.

Roberti et al., studied a total of 161 patients, $138(85.7 \%)$ females and $33(14.3 \%)$ males with mean age of 47 years and range of (10-81 years) [7]. While, Arvind et al., studied 500 cases, 335 $(67 \%)$ females and $165(33 \%)$ males with mean age 36 years and range of (2-65 years) [8]. In this current study, we operated upon a total of 30 patients, $13(43.3 \%)$ females and $17(56.6 \%)$ males 
with a mean age $19.367 \pm 18.213$ (SD). And range of $(11 \mathrm{~m} 59 \mathrm{y})$. This is quietly different from the for mentioned two studies as a regard of the predominance of female sex while Kalyani et al., is quietly near to this current study as the male gender represent $(69.3 \%)$ and females represent $(30.7 \%)$ [9]. Clinically headache, vomiting, and blurring of vision (50\% of the patients)and disturbance of gait (44\% of the patients) were the most common presenting symptoms, and cranial nerve abnormalities were the most common findings on neurological examination as found Roberti et al., [7]. This current study agrees with the preceding study where 27 (90\%) patients have complained of symptoms of Increased intracranial tension (headache, vomiting, and blurring of vision), 22 (75\%) patients have complained of equilibrium disturbances and 12 (40\%) patients have complained of vertigo. By examinations, $28(93.3 \%)$ patients had cerebellar syndrome, 12 (40\%) Patients had hydrocephalic changes, $6(20 \%)$ patients had cranial nerve dysfunction and only one $(3.33 \%)$ patient had a disturbed conscious level.

Sawaya et al., classified the complications associated with craniotomy into three major categories: Neurological, regional, and systemic complication [9]. In this study, we mainly focused on neurological and regional complications associated with posterior fossa surgery because they have been observed to occur with much greater frequency and are directly related to the surgical procedures.

Cerebrospinal fluid leakage is a common complication associated with cranial base surgery, Leaks usually occur in the immediate post-operative period, and they are clinically evident as clear spinal fluid drainage from the nose, ear, or incisional wound and it accounts for $25.8 \%$ of all complications $[\mathbf{1 0 , 1 1 ]}$. This current study showed that incisional CSF leak has occurred in four $(13.33 \%)$ patients. Cases of incisional CSF leak, are often secondary to an incomplete watertight dural closure [10]

Cranial nerve morbidity is also commonly encountered with posterior cranial fossa surgery. Deficit usually occurs as a result of nerve retraction, direct injury during operation, or compromise of its blood supply [12]. In this current study, it was occurred in 3 (10\%) patients in the form of bulbar palsy. Depending on the location of the lesions and the surgical approaches, the post-operative $\mathrm{CN}$ dysfunction may involve CN III to XII [13]. Injuries to lower CNs IX, X, XI, XII occur infrequently after posterior fossa surgery on large tumors that distort the nerves and displace them inferiorly against the occipital bone [14]. The post-operative complications that occurred most exclusively in cerebellar parenchymal tumor resection were posterior fossa edema and hematoma, hydrocephalus, and cerebellar mutism with incidences ranging from $1.2 \%$ to $5 \%[\mathbf{1 5 , 1 6 ]}$. In views of hydrocephalus, its occurrence in patients who underwent craniotomy for tumor resection is reported as $10 \%$ to $30 \%$. However, there is no well-documented literature concerning whether the hydrocephalus already existed pre-operatively [17]. Compared to the current study, the new onset post-operative hydrocephalus for patients after posterior fossa surgery was documented in six (20\%) patients which was secondary to forth ventricular obstruction by blood and treated surgically by ventriculoperitoneal shunt. The development of this de novo hydrocephalus seems to result from other postoperative complications such as edema, hematoma, and CSF infection either by direct obstruction of CSF flow or by impairment of CSF absorption. Intra-operative spillage of blood into the CSF cisterns and subarachnoid space can also cause hydrocephalus due to blood products clogging the arachnoid villi [18]

Post-operative infections range from superficial wound infection to deep infections that involve the bone flap or meninges. Some studies documented the risk to be $1 \%$ to $2 \%$ after supra-tentorial craniotomy $[9,19,20]$. When compared to the current study, no cases with wound infection were documented. Many factors increase the risk of infection, including persistent CSF leak, foreign body, long surgery, long-term use of steroids, and diabetics $[19,21]$. Reoperation and cytotoxic therapy have also been shown to increase the risk of craniotomy infection [22]

Roberti et al., observed 6 cases of cerebellar mutism [7]. Cerebellar mutism occurs mostly in children after the removal of posterior fossa tumors, although a few adult cases have also been described in the past [23-25]. In the current study, in the beginning of our work with the use of transvermian approach, only one $(3.33 \%)$ patient had postoperative mutism. Some authors have proposed that the involvement of the dentate nucleus may be responsible for the mutism [26,27]. Crutchfield et al., suggested that the disruption of the dentatothalamocortical pathway might be the cause of postoperative mutism [28]

\section{Conclusion:}

The surgical outcome of patients with intraaxial posterior cranial fossa tumors is good due to early correct diagnosis, the advent of microsurgical techniques, proper selection of the appropriate surgical approach and the proper treatment of postoperative complications. 


\section{References}

1- JOHNSON K.J., CULLEN J., BARNHOLTZ-SLOAN J.S., et al.: Childhood brain tumor epidemiology: A brain tumor epidemiology consortium review. Cancer. Epidemiol. Biomarkers Prev. Dec., 23 (12): 2716-36, 2014.

2- KAMIL M.A., YUSUF I., ALPER B., et al.: Surgical outcomes of cerebellar tumors in children. Pdiatr. Neurosurg., 40: 220-2, 2004.

3- LIN C.T. and RIVA-CAMBRIN J.K.: Management of posterior fossa tumors and hydrocephalus in children: a review. Childs. Nerv. Syst. Oct., 31 (10): 1781-9, 2015.

4- ARRIADA N. and SOTELO J.: Continuous-flow shunt for treatment of hydrocephalus due to lesions of the posterior fossa. J. Neurosurg. Nov.. 101 (5): 762-6, 2004.

5- JIANG C., WU X., LIN Z., et al.: External drainage with an Ommaya reservoir for perioperative hydrocephalus in children with posterior fossa tumors. Childs. Nerv. Syst. Mar., 17, 2013.

6- LAM S., REDDY G.D., LIN Y., et al.: Management of hydrocephalus in children with posterior fossa tumors. Surg. Neurol. Int., 6 (Suppl 11): S346-8, 2015.

7- ROBERTI F., SEKHAR L.N., KALAVAKONDA C., et al.: Posterior fossa meningiomas: Surgical experience in 161 cases. Surg. Neurol., 56: 8 -21, 2001.

8- ARVIND D., WEN-SHAN S., MARK S.H., et al.: Complications of posterior cranial fossa surgery: An institutional experience of 500 patients. Surgical Neurology, 72: 369-375, 2009.

9- KALYANI D., RAJYALAKSHMI S. and SRAVAN O.: Clinicopathological study of posterior fossa intracranial lesions. J. Med. Allied. Sci., 4 (2): 62-68, 2014.

10- SAWAYA R., HAMMOUD M., SCHOPPA D., et al. Neurosurgical outcomes in a modern series of 400 craniotomies for treatment of parenchymal tumors. Neurosurgery, 42: 1044-56, 1998.

11- FISHMAN A.J., MARRINAN M.S., GOLFINOS J.G., et al.: Prevention and management of cerebrospinal fluid leak following vestibular schwannoma surgery. Laryngoscope, 114: 501-5, 2004.

12- SEN C and SEKHAR L.: Complications of cranial base surgery. In: Post K., Friedman E., McCormick P., editors. Postoperative complications in intracranial neurosurgery. New York: Thieme, p. 111-33, 1993.

13- JENKINS A.L., DEUTCH H., PATEL N.P., et al.: Complication avoidance in neurosurgery. In: Winn HR, editor. Youmans Neurological Surgery, Vol. 1. Philadelphia: Saunders, p. 561-94, 2004.

14-DARROUZET V., MARTEL J., ENÉE V., et al.: Vestibular schwannoma surgery outcomes: Our multidisciplinary experience in 400 cases over 17 years. Laryngoscope, 114: 681-8, 2004.
15- SCHLAKE H.P., GOLDBRUNNER R.H., MILEWSKI C., et al.: Intra-operative electromyographic monitoring of the lower cranial motor nerves (LCN IX-XII) in skull base surgery. Clin. Neurol. Neurosurg., 103: 72-82, 2001.

16- JENKINS A.L., DEUTCH H., PATEL N.P., et al.: Complication avoidance in neurosurgery. In: Winn HR, editor. Youmans Neurological Surgery, Vol. 1. Philadelphia: Saunders, p. 561-94, 2004.

17- WARNICK R.E.: Surgical complications and their avoidance. In: Winn H.R., editor. Youmans Neurological Surgery, vol. 1. Philadelphia: Saunders, p. 931-40, 2004.

18- DUONG D.H., O'MALLEY S., SEKHAR L.N., et al.: Postoperative hydrocephalus in cranial base surgery. Skull. Base. Surg., 10: 197-200, 2000.

19- KOSTELJANETZ M.: CSF dynamics in patients with subarachnoid and/or intraventricular hemorrhage. J. Neurosurg., 60: 940-6, 1984.

20- CABANTOG A.M. and BERNSTEIN M.: Complications of first craniotomy for intra-axial brain tumor. Can. J. Neurol. Sci., 21: 213-8, 1994.

21- NAROTAM P.K., VAN DELLEN J.R., du TREVOU M.D., et al.: Operative sepsis in neurosurgery: A method of classifying surgical cases. Neurosurgery, 34: 409-15, 1994.

22- BENNETT M. and HAYNES D.S.: Surgical approaches and complications in the removal of vestibular schwannomas. Otolaryngol. Clin. North. Am., 40: 589-609, 2007.

23- BRELL M., IBÁÑEZ J., CARAL L., et al.: Factors influencing surgical complications of intra-axial brain tumors. Acta. Neurochir (Wien), 142: 739-50, 2000.

24- CAKIR Y., KARAKIŞI D. and KOÇANAOGULLARI O.: Cerebellar mutism in an adult: Case report. Surg. Neurol., 41: 342-4, 1994.

25- DOXEY D., BRUCE D., SKLAR F., et al.: Posterior fossa syndrome: Identifiable risk factors and irreversible complications. Pediatr. Neurosurg., 31: 131-6, 1999.

26- SALVATI M., MISSORI P., LUNARDI P., et al.: Transient cerebellar mutism after posterior cranial fossa surgery in an adult: Case report and review of the literature. Clin. Neurol. Neurosurg., 93: 313-6, 1991.

27- DIETZEJR D.D. and MICKLE J.P.: Cerebellar mutism after posterior fossa surgery. Pediatr. Neurosurg., 16: 2531, 1990-1991.

28- ERSAHIN Y., MUTLUER S., CAGLI S., et al.: Cerebellar mutism: report of seven cases and review of the literature. Neurosurgery, 3 8: 60-5, 1996.

29- CRUTCHFIELD J.S., SAWAYA R., MEYERS C.A., et al.: Postoperative mutism in neurosurgery. J. Neurosurg. 81: 115-21, 1994. 


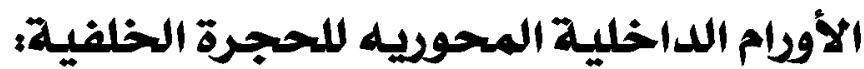 النتائج الجراحرية الجريحة}

الهدف: لتوثيق النتائج الجراحية على المدى القصير للأودام الداخلية المحوية للحجرة الخلفية فى المرضى الذين يعانون من

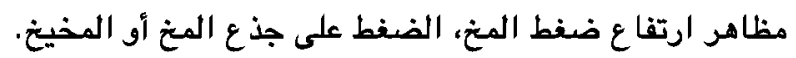

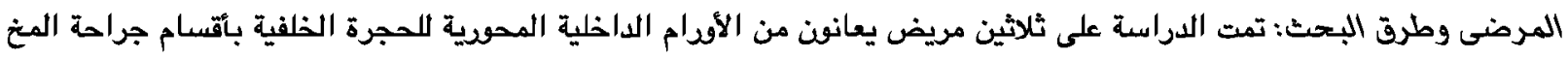

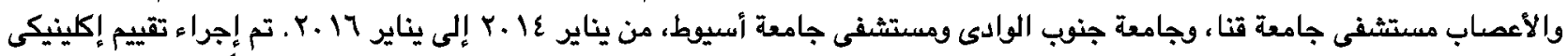

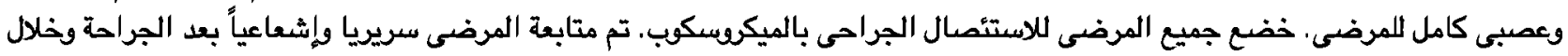
شهر واحد بعد الجراحة.

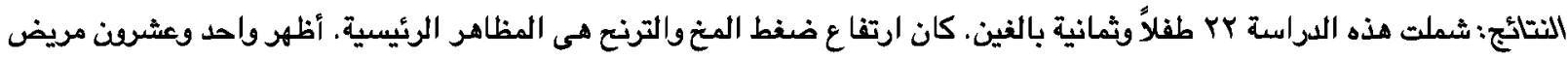

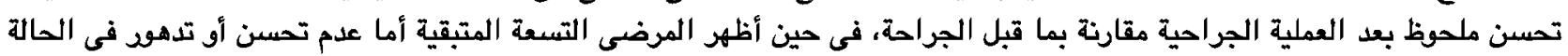

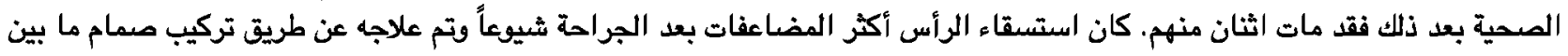
بطينات المخ والبريتون.

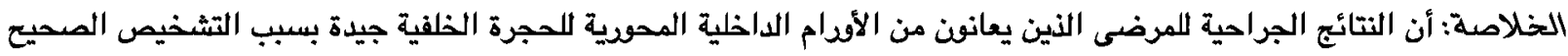
المبكر، ظهود تقنيات الجراحة الميكروسكوبيه، الاختيار الصحيح للطريقة الجراحية المناسبة والعلاج المناسب للمضاعفات التالية للعمليات 